\title{
Survival of Hospitalized COVID-19 Patients in Northern Italy: A Population-Based Cohort Study by the ITA-COVID-19 Network
}

This article was published in the following Dove Press journal: Clinical Epidemiology

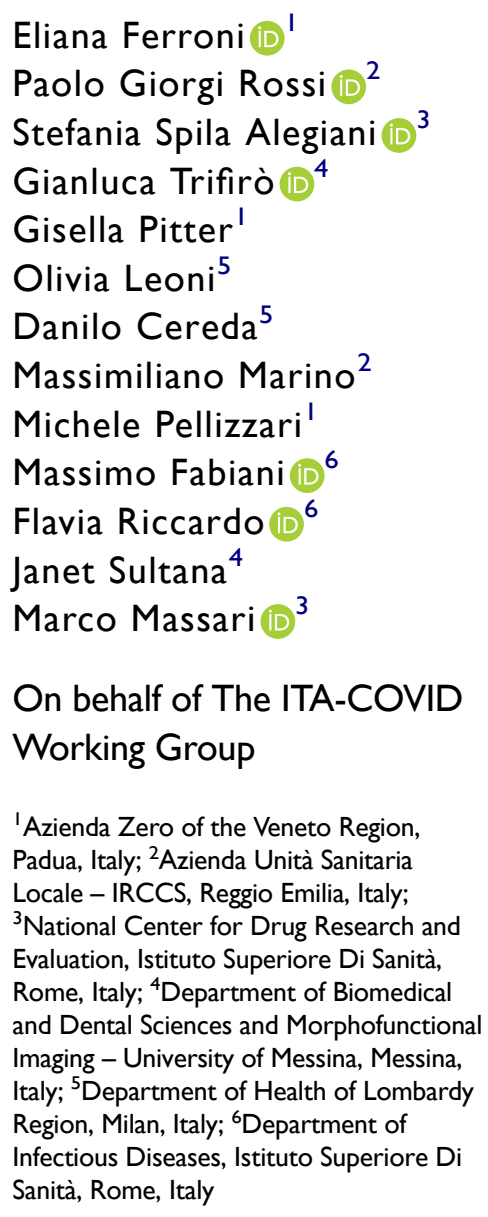

Correspondence: Stefania Spila Alegiani Istituto Superiore Di Sanità, Viale Regina Elena, 299, Rome 0016I, Italy

Tel +390649904249

$\mathrm{Fax}+390649904248$

Email stefania.spila@iss.it

Paolo Giorgi Rossi

Azienda Unità Sanitaria Locale - IRCCS,

Reggio Emilia, via Amendola 2, Reggio

Emilia 42I 22, Italy

Tel +390522335490

Email paolo.giorgirossi@ausl.re.it
Introduction: COVID-19 case fatality rate in hospitalized patients varies across countries and studies. Reliable estimates, specific for age, sex, and comorbidities, are needed to monitor the epidemic, to compare the outcome in different settings, and to correctly design trials for COVID-19 interventions. The aim of this study was to provide population-based survival curves of hospitalized COVID-19 patients.

Materials and Methods: A cohort study was conducted in three areas of Northern Italy, heavily affected by SARS-CoV-2 infection (Lombardy and Veneto Regions, and Reggio Emilia province), using a loco-regional COVID-19 surveillance system, linked to hospital discharge databases. We included all patients testing positive for SARS-CoV-2 RNA by RTPCR on nasopharyngeal/throat swab samples who were hospitalized from 21 February to 21 April 2020. Kaplan-Meier survival estimates were calculated at 14 and 30 days for death in any setting, stratifying by age, sex, and the Charlson Index.

Results: Overall, 42,926 hospitalized COVID-19 patients were identified. Patients' median age was 69 years (IQR: 57-79), 62.6\% were males, and 6.0\% had a Charlson Index $\geq 3$. Survival curves showed that $22.0 \%$ (95\% CI 21.6-22.4) of patients died within 14 days and $27.6 \%$ (95\% CI 27.2-28.1) within 30 days from hospitalization. Survival was higher in younger patients and in females. The negative impact of comorbidities on survival was more pronounced in younger age groups.

Conclusion: The high fatality rate observed in the study (28\% at 30 days) suggests that studies should focus on death as primary endpoint during a follow-up of at least one month. Keywords: COVID-19, survival, cohort study, hospitalized patients, Italy

\section{Introduction}

Severe acute respiratory syndrome coronavirus 2 (SARS-CoV-2) has spread rapidly on a global scale, ${ }^{1,2}$ with almost 24 million cases of coronavirus disease (COVID-19) being diagnosed worldwide. ${ }^{3}$ Italy was the first European country to be affected by COVID$19:^{3-5}$ as of 31 August 2020, more than 260,000 cumulative confirmed SARS-CoV-2 infections were reported, with an overall case fatality rate (CFR) of $13.8 \%{ }^{6}$

Despite the fact that the body of relevant epidemiological findings about the pandemic has grown rapidly, COVID-19 CFR is still debated. Reports from different countries show considerable heterogeneity in CFR, ranging from less than $1 \%$ to approximately $12 \% .^{3,7}$ Differences in age and the burden of comorbidities of cases may partially explain these differences, but differences in case detection and reporting (denominator) and how COVID-19-related deaths are defined (numerator) are also 
important sources of heterogeneity. In addition, the accuracy of CFR assessment is limited by disease ascertainment challenges, a bias in favor of including symptomatic and very sick patients, and variability in testing accuracy. ${ }^{8}$ Furthermore, the length of follow-up is essential to accurately measuring $\mathrm{CFR}^{9-11}$

Two recent systematic reviews of trials and observational studies (mainly from China) found a pooled CFR estimate of 3-4\%; ${ }^{12,13}$ instead, most reports from European countries have shown CFRs ranging from $10 \%$ to $20 \%$ when a cohort approach with adequate follow-up was conducted. ${ }^{9,14}$ Differences in CFR have also been reported in studies including only hospitalized COVID-19 patients. ${ }^{15-19}$ Reliable population-based estimates of CFR for hospitalized patients are essential for supporting clinical decision-making, providing standards to monitor the epidemic, and the performance of the health service. Furthermore, such a reference standard is needed to accurately design trials of interventions targeting COVID-19 with adequate statistical power and to give a counterfactual for Phase II, single-arm studies, a design that is often employed to test therapies in COVID-19 patients. As of 5 June 2020, 1163 interventional studies on COVID-19 patients were registered on clinicaltrials.gov (Figure S1); of these, 38.4\% were Phase II (including phase I/II and II/III) trials, and almost $50 \%$ of those studies were aimed at exploring survival as outcome (Figure S2). Given the rapid spread of the pandemic and the absence of any effective therapy, it is likely that new therapies, if proven to be promising in phase II studies, will be directly transferred to clinical practice without more rigorous testing of their efficacy in Phase III studies.

The aim of this study was therefore to provide population-based survival curves of hospitalized COVID-19 patients that can be used to monitor the impact of the epidemic and disease management as well as to design phase II trials and to correctly calculate the required sample size of phase III studies.

\section{Materials and Methods}

\section{Setting}

The study included patients living in the regions of Lombardy, the first and hardest hit Italian region (10 million inhabitants), and Veneto, where the second cluster was detected (4.9 million inhabitants), and Reggio Emilia province ( 0.5 million inhabitants), which is part of the Emilia-Romagna region, which ranked second in terms of the spread of the epidemic during the study period. The three areas included in the study represent $25 \%$ of the Italian population.
In Italy, the National Health Service provides all testing activities and acute care free of charge to all residents. All RTpolymerase chain reaction (PCR) SARS-CoV-2 tests performed in Italy must be recorded in the national case-based integrated surveillance system of all RT-PCR-confirmed cases of COVID-19. ${ }^{14}$ This surveillance system contains data on all COVID-19 patients, collected by local public health department during epidemiological investigations through: 1) daily reports from COVID-19 labs for all positive RT-PCR tests; 2) an initial epidemiological investigation conducted through phone interviews of all cases, followed by daily phone calls to patients cared for in outpatient settings carried out by the public health department of each local health authority; 3) daily reports extracted from electronic medical records for hospitalized patients, and 4) check of death records to assess mortality, particularly in outpatient settings (Figure S3). Although regional testing strategies differed due to local protocols and logistic constraints during the study period, patients in all the study areas with symptoms potentially suggesting COVID-19, who were admitted to the Emergency Room or hospital, were always tested.

\section{Study Population}

From the loco-regional COVID-19 integrated surveillance databases, all $\geq 18$ years patients with confirmed SARS-CoV -2 infection who were hospitalized between 21 February (date of the first Italian COVID-19 patient hospitalization) and 21 April 2020 were identified in Lombardy. Inclusion of all resident patients excluded any chance of selection bias. Patients hospitalized between 21 February and 31 March 2020 were identified in the other two study areas (Veneto and Reggio Emilia), based on data availability at the time, the study analyses were carried out. The admission date was considered as the index date. Patients were followed up until death or the end of the study period (21 April 2020 for all the three areas), whichever came first. To calculate the Charlson Index ${ }^{20}$ for each hospitalized COVID-19 patient, hospital discharge databases were linked to the loco-regional COVID-19 surveillance database to identify all hospital admissions within the 10 years preceding COVID-19 hospitalizations (Table S1); the use of pre-existing information avoided any ascertainment bias.

An R-based tool for distributed analyses (The ShinISS) developed by the Italian National Institute of Health was used by each study center to locally process COVID-19 patient data using the same data model in all centers, and only an anonymized dataset for central analysis was shared, in compliance with EU-GDPR regulations. 


\section{Outcome Measure}

The endpoint was death occurring during follow-up in an inpatient or outpatient setting for any cause, as reported in the loco-regional COVID-19 surveillance system. The outcome measures were mortality at 14 and 30 days from hospital admission and time to event was calculated from COVID-19 hospitalization to death or the end of follow-up, whichever came first.

\section{Statistical Analysis}

Univariate survival measures, with corresponding 95\% confidence intervals $(95 \% \mathrm{CI})$, at a fixed follow-up time (14 and 30 days) were computed with the Kaplan-Meier estimator for each covariate of interest: age $(<50,50-59,60-69,70-79$, $80-89$, and $\geq 90$ years), sex (males and females), and the Charlson Index $(0,1-2$, and $\geq 3)$. Furthermore, we present data for sex and for the Charlson Index stratified by age category. A Cox proportional hazards model was used to show the adjusted effect of sex, age, comorbidities, the Charlson Index, and study area, with an interaction term between age and the Charlson Index. Proportional hazards assumptions were verified on the basis of Schoenfeld residuals and significance was set at $p$-value $<0.05$. All statistical analyses were performed using STATA (version 16) and $\mathrm{R}$ (version 3.6).

\section{Results}

The three loco-regional COVID-19 surveillance systems captured data from 79,822 patients, of whom 35,671 were excluded because they did not meet the inclusion criteria (being hospitalized or above 18 years old). A further 1225 patients were excluded because their data could not be deterministically linked to the resident population registries. Overall, 42,926 hospitalized COVID-19 patients were included in the study; of these, 38,715 (90.2\%) were from Lombardy, 3229 (7.5\%) were from Veneto, and 982 (2.3\%) were from Reggio Emilia (Figure S3). Patients' median age was 69 years (interquartile range, IQR: 57-79 years), and $62.6 \%$ were males. The median time from hospitalization to death was 6 days (IQR: $3-12$ ); $69.4 \%$ of patients did not have any prior hospitalization reporting the presence of comorbidities included in the Charlson Index, while $6.0 \%$ had a Charlson Index $\geq 3$ (Table 1).

Table I Baseline Patient Characteristics, Deaths, and Case Fatality Rate per 1000 Person-Days, by Study Area, Age, Sex, and the Charlson Index

\begin{tabular}{|c|c|c|c|c|c|}
\hline & \multicolumn{2}{|c|}{ All patients } & \multirow{2}{*}{$\begin{array}{l}\text { Person-time } \\
\text { (days) }\end{array}$} & \multirow[t]{2}{*}{ No. deaths } & \multirow[t]{2}{*}{ CRF (per 1,000 p-d) } \\
\hline & No. & (\%) & & & \\
\hline Total & 42,926 & & $1,016,708$ & $\mathrm{II}, 205$ & 11.02 \\
\hline \multicolumn{6}{|l|}{ Study area } \\
\hline Lombardy & 38,715 & 90.2 & 965,129 & 10569 & 10.95 \\
\hline Veneto & 3229 & 7.5 & 39,640 & 439 & 11.07 \\
\hline Reggio $\mathrm{E}$. & 982 & 2.3 & 11,939 & 197 & 16.50 \\
\hline \multicolumn{6}{|l|}{ Age, years } \\
\hline $18-49$ & 5561 & 13.0 & 159,252 & $|4|$ & 0.89 \\
\hline $50-59$ & 7172 & 16.7 & 204,144 & 451 & 2.21 \\
\hline $60-69$ & 8754 & 20.4 & 233,431 & 1484 & 6.36 \\
\hline $70-79$ & 10,953 & 25.5 & 244,025 & 3867 & 15.85 \\
\hline $80-89$ & 8880 & 20.7 & 154,177 & 4343 & 28.17 \\
\hline$\geq 90$ & 1606 & 3.7 & 21,679 & 919 & 42.39 \\
\hline \multicolumn{6}{|l|}{ Gender } \\
\hline Males & 26,873 & 62.6 & 635,776 & 7662 & 12.05 \\
\hline Females & 16,053 & 37.4 & 380,932 & 3543 & 9.30 \\
\hline \multicolumn{6}{|l|}{ Charlson index } \\
\hline 0 & 29,775 & 69.4 & 753,537 & 5805 & 7.70 \\
\hline $\mathrm{I}-2$ & 10,575 & 24.6 & 220,501 & 4018 & 18.22 \\
\hline$\geq 3$ & 2576 & 6.0 & 42,670 & 1382 & 32.39 \\
\hline
\end{tabular}

Abbreviation: No, number; CFR, Case Fatality Rate; p-d, person-days; Reggio E., Reggio Emilia. 
The survival curves showed that $22.0 \%$ (95\% CI 21.6-22.4\%) and $27.6 \%$ (95\% CI $27.2-28.1 \%)$ of patients died within 14 (Table S2) and 30 days from hospital admission, respectively (Table 2). The curve had similar trajectories for all age groups, although the survival rate was higher in patients aged $<50$ years $(2.8 \%$ died at 30 days) and those aged $50-59$ years $(6.7 \%$ died at 30 days). Instead, patients aged 80-89 years and $\geq 90$ years had a lower survival rate $(52.5 \%$ and $64.9 \%$ died at 30 days, respectively). Survival rates were also higher among females both at 14 and 30 days from admission (18.7\% and $23.7 \%$, respectively). The proportion of deaths occurring at 30 days was higher in patients with comorbidities: $20.7 \%, 40.2 \%$, and $58.1 \%$ for those with a Charlson Index of $0,1-2$, and $\geq 3$, respectively (Figure 1, Table 2).
The difference in survival between males and females was similar across all age groups (Tables S2 and 2, Figure S4), with the hazard ratio (HR) for females vs males equal to 0.66 (95\% CI: $0.63-0.68)$ when adjusting for age, Charlson index, and study area (Table 3). The negative effect of comorbidities on survival was more pronounced in younger patients, and it gradually decreased with age as shown by the interaction terms below one (Table 3, Figure 2).

\section{Discussion}

In this large population-based cohort of Italian hospitalized COVID- 19 patients, we observed a $27.6 \%$ fatality rate at one month from hospital admission. The fatality rate was slightly higher in males (29.9\%) than in females (25.7\%),

Table 2 Proportion of Surviving Patients at 30 Days from Hospitalization, Estimated Using the Kaplan-Meier Survival Function, by Study Area, Age, Sex, and the Charlson Index

\begin{tabular}{|c|c|c|c|c|c|c|c|}
\hline & \multicolumn{7}{|c|}{ Cumulative survival rate $\%(95 \% \mathrm{Cl})$} \\
\hline & \multirow[t]{2}{*}{ All patients } & \multicolumn{6}{|c|}{ Age category } \\
\hline & & 1 8-49 years & $50-59$ years & 60-69 years & 70-79 years & 80-89 years & $\geq 90$ years \\
\hline Overall & $\begin{array}{l}72.4 \\
(71.9-72.8)\end{array}$ & $\begin{array}{l}97.2 \\
(96.0-97.7)\end{array}$ & $\begin{array}{l}93.3 \\
(92.0-94.0)\end{array}$ & $\begin{array}{l}82.0 \\
(81.0-82.9)\end{array}$ & $\begin{array}{l}63.0 \\
(62.0-64.0)\end{array}$ & $\begin{array}{l}47.5 \\
(46.4-48.7)\end{array}$ & $\begin{array}{l}35.1 \\
(32.4-38.0)\end{array}$ \\
\hline \multicolumn{8}{|l|}{ Study area } \\
\hline Lombardy & $\begin{array}{l}71.9 \\
(71.5-72.4)\end{array}$ & $\begin{array}{l}97.1 \\
(96.6-97.6)\end{array}$ & $\begin{array}{l}93.3 \\
(92.7-93.9)\end{array}$ & $\begin{array}{l}81.5 \\
(80.6-82.4)\end{array}$ & $\begin{array}{l}62.0 \\
(61.0-63.0)\end{array}$ & $\begin{array}{l}46.6 \\
(45.4-47.8)\end{array}$ & $\begin{array}{l}34.4 \\
(31.5-37.4)\end{array}$ \\
\hline Veneto & $\begin{array}{l}72.8 \\
(69.0-76.5)\end{array}$ & $\begin{array}{l}99.5 \\
(98.5-100)\end{array}$ & $\begin{array}{l}94.6 \\
(91.5-97.7)\end{array}$ & $\begin{array}{l}86.6 \\
(77.9-96.2)\end{array}$ & $\begin{array}{l}68.7 \\
(61.4-77.0)\end{array}$ & $\begin{array}{l}52.4 \\
(45.6-60.2)\end{array}$ & $\begin{array}{l}37.3 \\
(27.3-5 I . I)\end{array}$ \\
\hline Reggio $\mathrm{E}$. & $\begin{array}{l}71.1 \\
(66.5-76.0)\end{array}$ & - & $\begin{array}{l}90.3 \\
(83.1-98.1)\end{array}$ & $\begin{array}{l}83.2 \\
(73.3-94.5)\end{array}$ & $\begin{array}{l}69.1 \\
(59.6-80.1)\end{array}$ & $\begin{array}{l}59.2 \\
(52.0-67.4)\end{array}$ & $\begin{array}{l}39.4 \\
(26.5-58.6)\end{array}$ \\
\hline \multicolumn{8}{|l|}{ Sex } \\
\hline Males & $\begin{array}{l}70.1 \\
(69.0-70.7)\end{array}$ & $\begin{array}{l}96.6 \\
(96.0-97.3)\end{array}$ & $\begin{array}{l}92.0 \\
(91.0-92.8)\end{array}$ & $\begin{array}{l}79.4 \\
(78.0-80.5)\end{array}$ & $\begin{array}{l}58.7 \\
(57.5-59.9)\end{array}$ & $\begin{array}{l}41.1 \\
(39.6-42.6)\end{array}$ & $\begin{array}{l}28.6 \\
(24.5-33.3)\end{array}$ \\
\hline Females & $\begin{array}{l}76.3 \\
(75.0-77.0)\end{array}$ & $\begin{array}{l}98.1 \\
(97.0-98.7)\end{array}$ & $\begin{array}{l}96.1 \\
(95.0-96.9)\end{array}$ & $\begin{array}{l}87.7 \\
(86.4-89.1)\end{array}$ & $\begin{array}{l}71.5 \\
(70.0-73.1)\end{array}$ & $\begin{array}{l}56.0 \\
(54.3-57.8)\end{array}$ & $\begin{array}{l}39.2 \\
(35.7-42.9)\end{array}$ \\
\hline \multicolumn{8}{|c|}{ Charlson index } \\
\hline 0 & $\begin{array}{l}79.3 \\
(78.0-79.8)\end{array}$ & $\begin{array}{l}97.7 \\
(97.0-98.1)\end{array}$ & $\begin{array}{l}94.5 \\
(93.9-95.1)\end{array}$ & $\begin{array}{l}85.5 \\
(84.0-86.4)\end{array}$ & $\begin{array}{l}67.2 \\
(66.0-68.4)\end{array}$ & $\begin{array}{l}51.7 \\
(50.1-53.3)\end{array}$ & $\begin{array}{l}38.7 \\
(34.9-42.9)\end{array}$ \\
\hline $\mathrm{I}-2$ & $\begin{array}{l}59.8 \\
(58.8-60.8)\end{array}$ & $\begin{array}{l}92.0 \\
(89.0-95.0)\end{array}$ & $\begin{array}{l}87.9 \\
(85.6-90.2)\end{array}$ & $\begin{array}{l}73.8 \\
(71.7-76.0)\end{array}$ & $\begin{array}{l}59.5 \\
(57.8-6 \mid .2)\end{array}$ & $\begin{array}{l}45.6 \\
(43.7-47.4)\end{array}$ & $\begin{array}{l}34.4 \\
(30.2-39.3)\end{array}$ \\
\hline$\geq 3$ & $\begin{array}{l}41.9 \\
(39.8-44.1)\end{array}$ & $\begin{array}{l}75.4 \\
(60.0-94.7)\end{array}$ & $\begin{array}{l}64.3 \\
(54.2-76.3)\end{array}$ & $\begin{array}{l}55.9 \\
(50.3-62.1)\end{array}$ & $\begin{array}{l}43.7 \\
(40.1-47.6)\end{array}$ & $\begin{array}{l}36.6 \\
(33.5-40.0)\end{array}$ & $\begin{array}{l}23.4 \\
(16.8-32.5)\end{array}$ \\
\hline
\end{tabular}

Abbreviation: $95 \% \mathrm{Cl}$, 95\% confidence interval; Reggio E., Reggio Emilia. 
A

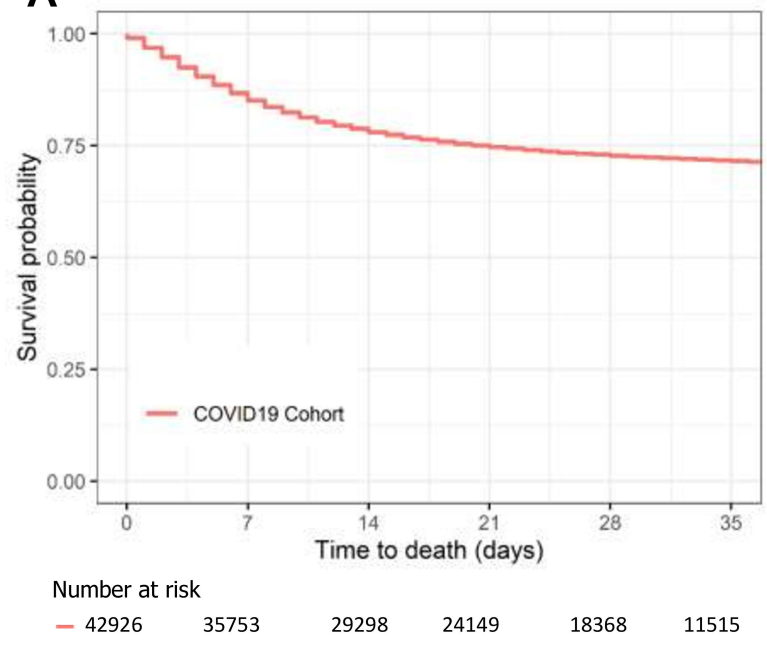

\section{C}

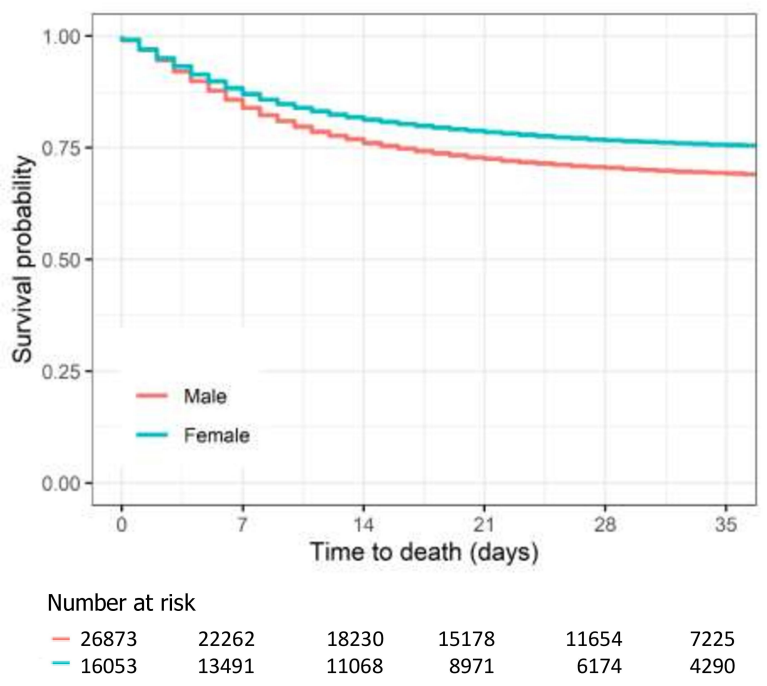

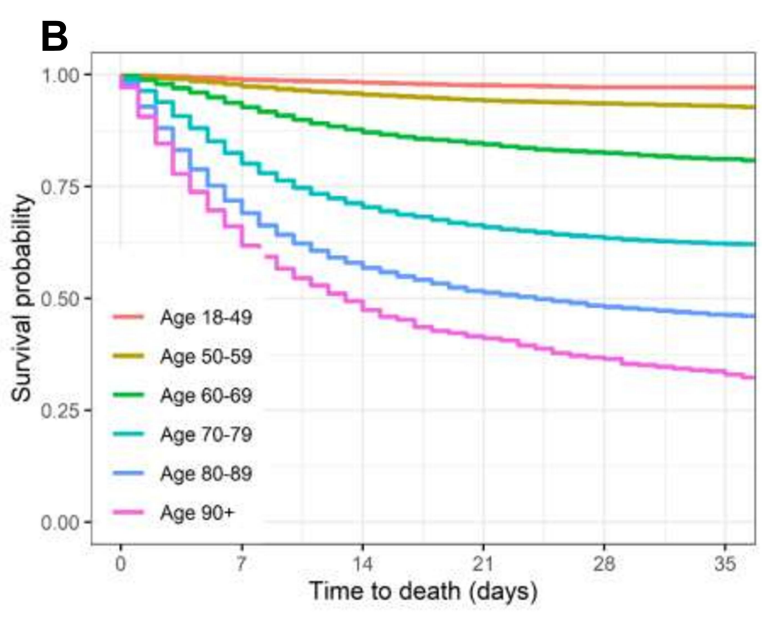

Number at risk

$\begin{array}{rrrrrr}-5561 & 5274 & 4701 & 3959 & 3108 & 1993 \\ -7172 & 6759 & 6003 & 5189 & 4063 & 2491 \\ -8754 & 7920 & 6812 & 5808 & 4497 & 2764 \\ -10953 & 8766 & 6922 & 5647 & 4201 & 2687 \\ -8880 & 6066 & 4274 & 3164 & 2250 & 1431 \\ -1606 & 968 & 586 & 382 & 249 & 149\end{array}$

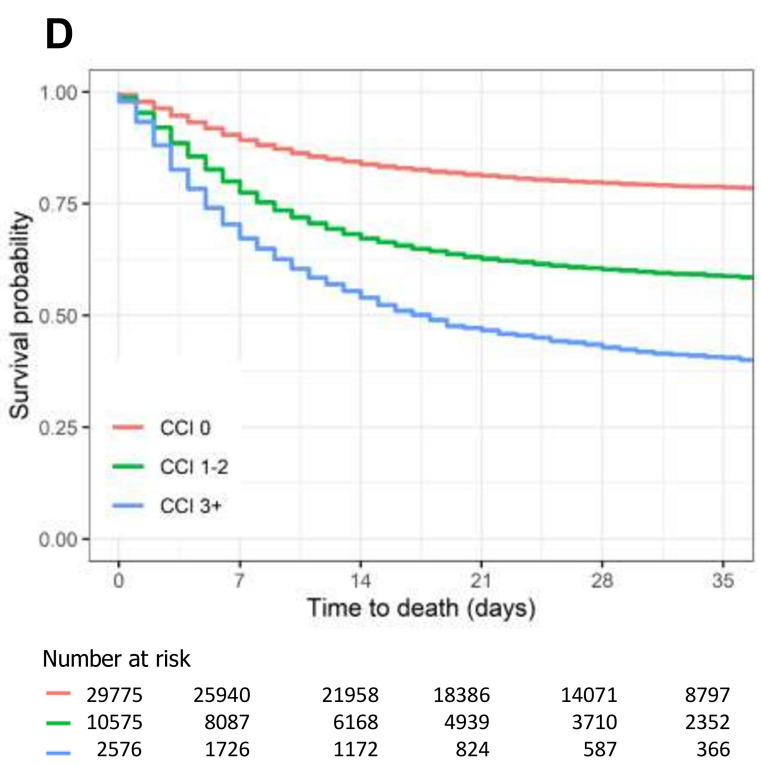

Figure I Kaplan-Meier survival curves for hospitalized COVID-19 patients in Northern Italy, 2 I February-2I April 2020. (A): overall; (B): stratified by age groups; (C): stratified by sex at birth; (D): stratified by the Charlson Index.

and this difference dramatically increased in the oldest age groups. The burden of comorbidities, measured using the Charlson Index, was an important prognostic factor in younger patients, while its impact on fatality rate in patients aged $\geq 80$ years was smaller, as probably the overall frailty of those patients was per se a very strong predictor of death.

We observed a much higher overall CFR in our study than did initial reports from other countries on hospitalized cohorts, where death rates rarely reached $20 \%{ }^{12,13,16}$ The variability in age structure and proportion of patients with comorbidities does not seem to explain all the observed differences in CFR across geographic areas. Several hypotheses have been proposed, including different viral strains causing more or less severe disease, differing capacities of the healthcare systems to respond to the COVID19 crisis as well as different case definitions, with some countries including probable cases in the overall death toll. The CFR can increase in some areas if there is a surge of infected patients, which adds to the strain on the healthcare system and can overwhelm its available medical resources. $^{21}$ Recently, population-based studies from countries with a similar dynamic of the epidemic spread and 
Table 3 Risk of Death for Hospitalized COVID-19 Patients, Estimated Using Cox Proportional Hazards Models for Age, Sex, and Charlson Index. The Model is Adjusted for All Reported Variables and Study Area and Shows the Interaction Between Charlson Index and Age

\begin{tabular}{|c|c|c|c|}
\hline & $\begin{array}{l}\text { HR (95\% CI) } \\
\text { Unadjusted }\end{array}$ & $\begin{array}{l}\text { HR }(95 \% \mathrm{CI}) \\
\text { Adjusted }\end{array}$ & $\begin{array}{l}\text { HR }(95 \% \mathrm{CI}) \\
\text { Adjusted* }\end{array}$ \\
\hline \multicolumn{4}{|l|}{ Age, years } \\
\hline $18-49$ & ref & ref & ref \\
\hline $50-59$ & $\begin{array}{l}2.49 \\
(2.06-3.01)\end{array}$ & $\begin{array}{l}2.39 \\
(1.98-2.89)\end{array}$ & $\begin{array}{l}2.43 \\
(1.95-3.02)\end{array}$ \\
\hline $60-69$ & $\begin{array}{l}7.04 \\
(5.92-8.37)\end{array}$ & $\begin{array}{l}6.46 \\
(5.44-7.68)\end{array}$ & $\begin{array}{l}6.60 \\
(5.40-8.06)\end{array}$ \\
\hline $70-79$ & $\begin{array}{l}16.8 \\
(14.2-19.8)\end{array}$ & $\begin{array}{l}14.8 \\
(12.5-17.5)\end{array}$ & $\begin{array}{l}17.8 \\
(|4.7-2| .7)\end{array}$ \\
\hline $80-89$ & $\begin{array}{l}27.6 \\
(23.3-32.6)\end{array}$ & $\begin{array}{l}24.3 \\
(20.5-28.8)\end{array}$ & $\begin{array}{l}31.7 \\
(26.1-38.5)\end{array}$ \\
\hline$\geq 90$ & $\begin{array}{l}37.5 \\
(31.4-44.8)\end{array}$ & $\begin{array}{l}36.2 \\
(30.3-43.3)\end{array}$ & $\begin{array}{l}52.6 \\
(42.6-65.0)\end{array}$ \\
\hline \multicolumn{4}{|l|}{ Sex } \\
\hline Males & ref & ref & ref \\
\hline Females & $\begin{array}{l}0.77 \\
(0.74-0.80)\end{array}$ & $\begin{array}{l}0.66 \\
(0.63-0.68)\end{array}$ & $\begin{array}{l}0.65 \\
(0.63-0.68)\end{array}$ \\
\hline \multicolumn{4}{|l|}{ Charlson Index } \\
\hline 0 & ref & ref & ref \\
\hline $\mathrm{I}-2$ & $\begin{array}{l}2.24 \\
(2.15-2.33)\end{array}$ & $\begin{array}{l}1.32 \\
(1.26-1.37)\end{array}$ & $\begin{array}{l}3.74 \\
(2.45-5.70)\end{array}$ \\
\hline$\geq 3$ & $\begin{array}{l}3.65 \\
(3.44-3.87)\end{array}$ & $\begin{array}{l}1.76 \\
(1.66-1.87)\end{array}$ & $\begin{array}{l}15.2 \\
(7.08-32.7)\end{array}$ \\
\hline \multicolumn{4}{|l|}{ Sex $x$ Charlson Index } \\
\hline Age $18-49 \times \mathrm{CCl} 0$ & & & ref \\
\hline Age $50-59 \times \mathrm{CCl} \mathrm{I}-2$ & & & $\begin{array}{l}0.67 \\
(0.42-1.08)\end{array}$ \\
\hline Age $60-69 \times \mathrm{CCl} \mathrm{I-2}$ & & & $\begin{array}{l}0.53 \\
(0.34-0.8 I)\end{array}$ \\
\hline Age $70-79 \times \mathrm{CCl} \mathrm{I-2}$ & & & $\begin{array}{l}0.34 \\
(0.22-0.52)\end{array}$ \\
\hline Age $80-89 \times \mathrm{CCl} \mathrm{I-2}$ & & & $\begin{array}{l}0.31 \\
(0.20-0.48)\end{array}$ \\
\hline Age $\geq 90 \times \mathrm{CCl} \mathrm{I}-2$ & & & $\begin{array}{l}0.26 \\
(0.17-0.4 I)\end{array}$ \\
\hline Age $50-59 \times \mathrm{CCl} \geq 3$ & & & $\begin{array}{l}0.46 \\
(0.20-1.08)\end{array}$ \\
\hline
\end{tabular}

(Continued) 
Table 3 (Continued).

\begin{tabular}{|l|l|l|l|}
\hline & $\begin{array}{l}\text { HR (95\% Cl) } \\
\text { Unadjusted }\end{array}$ & $\begin{array}{l}\text { HR (95\% Cl) } \\
\text { Adjusted }\end{array}$ & $\begin{array}{l}\text { HR (95\% CI) } \\
\text { Adjusted* }\end{array}$ \\
\hline Age $60-69 \times \mathrm{CCl} \geq 3$ & & & $\begin{array}{l}0.25 \\
(0.1 \mathrm{I}-0.54)\end{array}$ \\
\hline Age $70-79 \times \mathrm{CCl} \geq 3$ & & & 0.13 \\
& & & $(0.06-0.28)$ \\
\hline Age $80-89 \times \mathrm{CCl} \geq 3$ & & & 0.09 \\
& & & $(0.04-0.20)$ \\
\hline Age $\geq 90 \times \mathrm{CCl} \geq 3$ & & & 0.07 \\
& & & $(0.03-0.16)$ \\
\hline
\end{tabular}

Notes: *Interpretation of $\mathrm{HR}$ with the interaction term: in the model with the interaction terms, the $\mathrm{HRs}$ of $\mathrm{CCl}$ decline with increasing age. For instance, the $\mathrm{HR}$ of $\mathrm{CCl} 3+$ for the age class $50-59$ is equal to the $\mathrm{HR}$ of $\mathrm{CCl} 3+(15.2)$ multiplied by the interaction term of $\mathrm{CCl} 3+$ and age class $50-59(0.46)->\mathrm{I} 5.2 \times 0.46$ $=6.99$. Similarly, $\mathrm{HR}$ for $\mathrm{CCl} 3+$ and age $70-79$ is equal to $15.2 \times 0.13=1.98$.

Abbreviations: HR: hazard ratio; Cl: confidence interval; ref.: reference; $\mathrm{CCl}$ : Charlson Comorbidity Index

similar age structure of the population showed CFRs comparable to our estimates. A study conducted in the UK on 20,133 patients hospitalized for COVID-19 found a CFR of $26 \% .^{22}$ Data from hospitalized COVID-19 patients in New York City showed a CFR of $20 \%$ at approximately 6 days of follow-up. ${ }^{18}$ This figure seems much higher than survival during the first week following hospitalization in our study; however, this fatality rate for the New York population, which showed an average Charlson Index $>4$, is consistent with our specific estimate for the population with a Charlson Index $\geq 3$, which ranges from $20 \%$ to $25 \%$. Two other studies from the US recently reported $17 \%$ in-
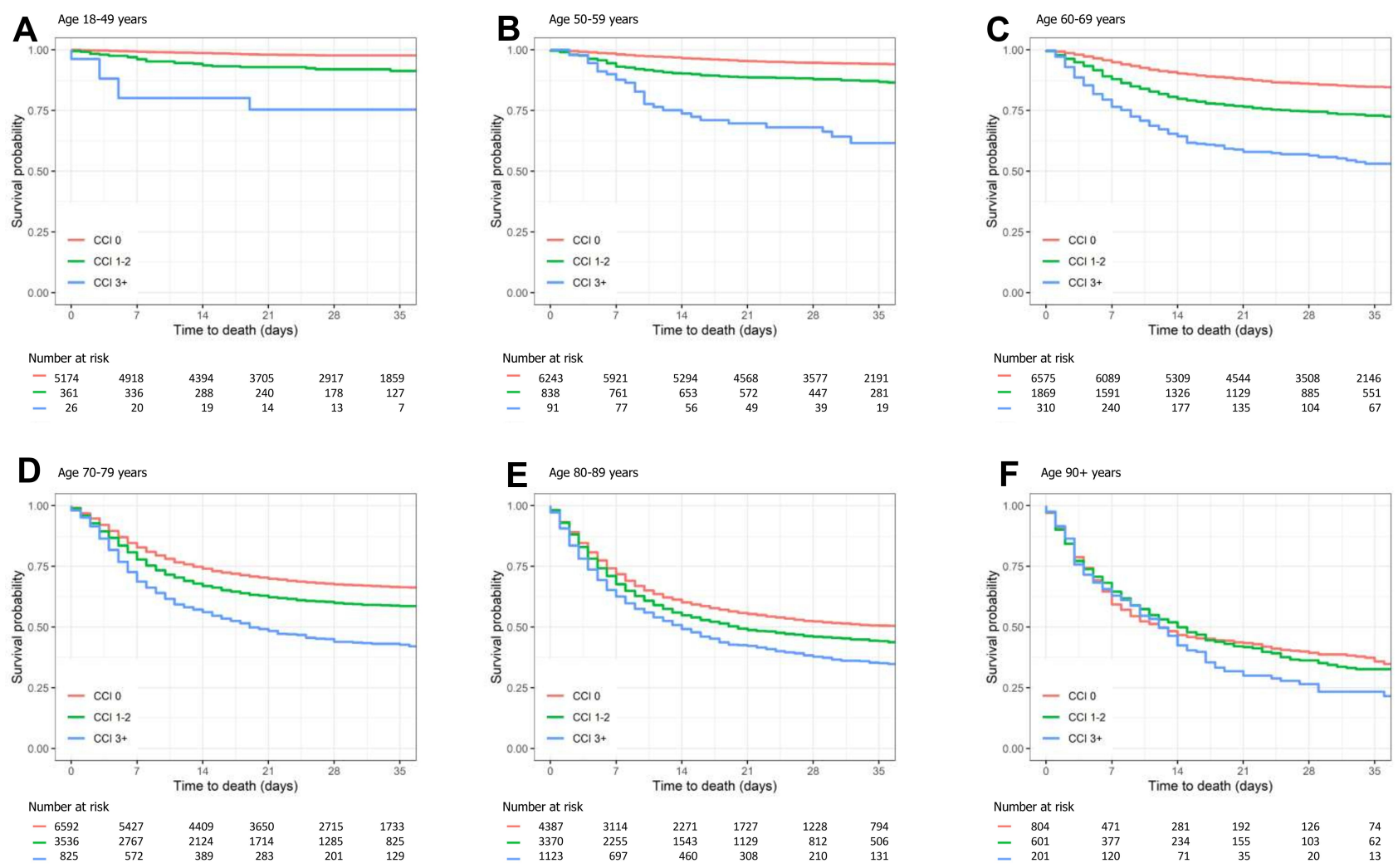

Figure 2 Kaplan-Meier survival curves for hospitalized COVID-19 patients in Northern Italy stratified by age and the Charlson Index, 2I February-2I April 2020. (A): age 18-49 years; (B): age 50-59 years; (C): age 60-69 years; (D): age 70-79 years; (E): age 80-89 years; (F): age 90+ years. 
hospital mortality after 7 days of follow-up ${ }^{23}$ and $24 \%$ after 21 days. ${ }^{24}$ Thus, considering the possible bias that can lead to over or underestimation of CFR in cohort studies, the population-based nature of our study can exclude the possible bias due to selection of participant hospitals and that due to short and/or incomplete follow-up or assessment of in-hospital mortality only.

The impact of age on the risk of death was dramatic in our cohort, in line with all previous studies. ${ }^{7,14}$ The excess risk cannot be entirely attributed to the burden of comorbidities, usually more frequent in advanced age. In fact, comorbidities appear to be an important predictor of death in COVID-19 patients in our cohort, in agreement with all previous epidemiologic investigations; ${ }^{16,17}$ however, their negative impact on survival is much more pronounced in younger than older patients. In our study design, the assessment of pre-existing comorbidities is independent from the outcome as this information is collected through the analysis of patient use of healthcare services in the years preceding the epidemic. Therefore, even if we may underestimate the presence of comorbidities, this misclassification is not differential in severe or fatal cases and in non-severe cases; the hazard ratios should thus be unbiased. On the other hand, because we included only hospitalized patients, our study may be affected by a selection bias that could lead to a collider effect. This bias can create associations that are not causal or may hide existing associations because some characteristics can affect the probability of being hospitalized. In this case, it is possible that we underestimated the impact of comorbidities because they can increase the probability of being hospitalized more than the probability of dying of COVID-19; the net effect would thus inflate the denominator and dilute the fatality risk of people with comorbidity in this cohort.

The availability of life-sustaining therapies or the lack thereof should be considered when interpreting the COVID-19 mortality rate. Poor outcomes may be due to known risk factors such as old age, frailty, comorbidities, or profound disability, or because of effects of logistic limitations associated with the lack of medical staff and/ or medical staff burn-out, and/or lack of beds and/or of medical supplies. Moreover, although patients might indeed have SARS-CoV-2 infection, the infection itself may not necessarily be the cause of death, as in patients with metastatic cancer or terminal organ failure. ${ }^{25}$
Since the healthcare system in Italy is regionally based, the early response to the COVID-19 epidemic varied across regions. Thus, the observed differences in the spread of the infection in the study area were due both to the different size of the initial clusters, much larger in Lombardy, where there was already a widespread dissemination (in Codogno and Alzano/Nembro), than in Veneto (Vò Euganeo), and to the regional control strategies implemented.

Lombardy suffered the fastest progression of the epidemic and initially responded with a rapid intensification of regional surveillance through contact tracing and testing contacts of all positive cases, but it was not enough to contain the outbreaks. Therefore, in a "scenario of widespread dissemination", ${ }^{26}$ the objective shifted from containment to mitigation, with a strong action on expanding hospital services, including intensive care, to meet the increased need for hospitalization and ICUs beds. ${ }^{27}$ In Veneto, strict containment of the outbreak was initially successful, allowing contact tracing for the entire epidemic peak. Reggio Emilia, whose outbreak was related to the expansion of the cluster of Codogno, faced an "intermediate" situation between the two regions. As of 21 April 2020, the proportion of positive tests out of the total number of swabs performed was $24.5 \%$ in Lombardy, $6.1 \%$ in Veneto, and $17.1 \%$ in Emilia-Romagna. ${ }^{28}$

Moreover, clinical criteria that must be met for COVID19 hospital admission may also vary among regions, principally due to a different organization of primary care and the availability of hospital beds, which varied in different places and moments of the epidemic, and the availability of other options for managing less severe patients, such as homebased treatment with monitoring. Where special units for home-based care for COVID-19 patients were activated, patients were treated and followed up at home, whenever possible. Nevertheless, CFRs in the three study areas became similar after an adequate follow-up (30 days), suggesting that regional differences in epidemic control strategies and in clinical criteria for hospital admission did not greatly affect our estimates, supporting the generalizability of the results.

\section{Conclusion}

In Northern Italy, during the peak of the epidemic (ie, February to April 2020), the case fatality rate of COVID19 hospitalized patients at 30 days from admission was about $28 \%$. Phase II clinical trials with follow-up shorter than 30 days from hospitalization may not capture all deaths related to COVID-19, ultimately leading to a potential 
overestimation of the benefits for the investigated COVID19 intervention in the absence of a comparator.

Reliable CFR and survival curves estimates should guide healthcare leaders and policymakers in developing public health strategies at national and international levels.

\section{Abbreviations}

SARS-CoV-2, severe acute respiratory syndrome coronavirus 2; COVID-19, coronavirus disease; CFR, case fatality rate; PCR, polymerase chain reaction; 95\% CI, 95\% confidence intervals; IQR, interquartile range; HR, hazard ratio; No, number; ref, reference; CCI, Charlson Index.

\section{Ethics Approval}

The study protocol was approved by the Ethics Committee of the Italian National Institute of Health on 19 March 2020 (n. 0009940) and subsequently by the local Institutional Review Board or Ethics Committee.

Aggregate data are available upon request to the local competent authorities. Queries should include information on research objectives and a protocol for analyses.

\section{Acknowledgments}

ITA-COVID19 Working Group: Istituto Superiore di Sanità (Italy): Stefania Spila Alegiani, Marco Massari, Francesca Menniti Ippolito, Roberto Da Cas, Graziano Onder, Massimo Fabiani, Flavia Riccardo, Antonino Bella, Patrizio Pezzotti; University of Messina Department of Biomedical and Dental Sciences and Morphofunctional Imaging, Messina (Italy) \& Italian Society of Pharmacology, Milan (Italy): Gianluca Trifirò, Janet Sultana, Valentina Ientile, Salvatore Crisafulli; Azienda Unità Sanitaria Locale - IRCCS, Reggio Emilia (Italy): Paolo Giorgi Rossi, Roberto Grilli, Giulio Formoso, Massimiliano Marino, Massimo Vicentini; Lombardy Region - Directorate General for Health, Milan (Italy): Olivia Leoni, Danilo Cereda, Monica Ludergnani, Annalisa Bodina, Ambra Castrofino, Francesca Grosso, Gabriele del Castillo, Marcello Tirani; Veneto Region - Azienda Zero, Padova (Italy): Eliana Ferroni, Gisella Pitter, Michele Pellizzari, Manuel Zorzi, Elena Narne, Ugo Fedeli, Mario Saia.

\section{Author Contributions}

EF, PGR, MMas, GT, and SSA contributed to the literature search, study design, data collection, data analysis, data interpretation, and to writing the manuscript.
GP, OL, and DC contributed to the literature search, study design data, data collection and data interpretation.

MMas, MMar, MP, and SSA contributed to data collection, software programming, data analysis, and data interpretation.

MF and FR conceived of and designed the surveillance system and collected data at the national level.

JS edited the final version of the manuscript and contributed to literature search and data visualization.

All authors contributed to data analysis, drafting or revising the article, have agreed on the journal to which the article will be submitted, gave final approval of the version to be published, and agree to be accountable for all aspects of the work.

\section{Disclosure}

Eliana Ferroni, Paolo Giorgi Rossi, Stefania Spila Alegiani, Gisella Pitter, Olivia Leoni, Danilo Cereda, Massimo Fabiani, Flavia Riccardo, Massimiliano Marino, Michele Pellizzari, and Marco Massari declare no competing interests.

Gianluca Trifirò reports grants from Novartis, from the Italian Drug Agency, during the conduction of the study. He has participated in advisory boards within the last five years on topics not related to this manuscript and organized by Sandoz, Hospira, Sanofi, Biogen, Ipsen, Shire and is a consultant for Otsuka. He is the principal investigator of observational studies of the University of Messina funded by several pharmaceutical companies (eg, Amgen, AstraZeneca, Daiichi Sankyo, IBSA) as well as scientific coordinator of the Master's program "Pharmacovigilance, pharmacoepidemiology and pharmacoeconomics: real-world data evaluations" at the University of Messina, which receives unconditional funding from several pharmaceutical companies. The authors report no other conflicts of interest in this work.

\section{References}

1. Yuan J, Li M, Lv G, et al. Monitoring Transmissibility and Mortality of COVID-19 in Europe. Int $J$ Infect Dis. 2020;95:311-315. doi:10.1016/j.ijid.2020.03.050

2. Liu Y, Gayle AA, Wilder-Smith A, et al. The reproductive number of COVID-19 is higher compared to SARS coronavirus. J Travel Med. 2020. doi: $10.1093 / \mathrm{jtm} / \mathrm{taaa} 021$

3. Dong E, Du H, Gardner L. An interactive web-based dashboard to track COVID-19 in real time. Lancet. 2020;20(5):533-534. doi:10.1016/S1473-3099(20)30120-1

4. Cereda D, Tirani M, Rovida F, et al. The early phase of the COVID-19 outbreak in Lombardy, Italy. arXiv Org Quant Biol. 2020.

5. Saglietto A, Biondi Zoccai G, Ferrari G, et al. COVID-19 in Europe: the Italian lesson. Lancet. 2020;30690-5:s0140-S6736. doi:10.1016/ S0140-6736(20)30690-5 
6. Istituto Superiore di Sanità. COVID-19 integrated surveillance data in Italy; 2020. Available from: https://www.epicentro.iss.it/corona virus/sars-cov-2-dashboard.

7. Onder G, Rezza G, Brusaferro S. Case-Fatality Rate and Characteristics of Patients Dying in Relation to COVID-19 in Italy. JAMA. 2020. doi:10.1001/jama.2020.4683

8. Wu Z, McGoogan JM. Characteristics of and important lessons from the coronavirus disease 2019 (COVID-19) Outbreak in China: summary of a report of 72314 cases from the Chinese Center for Disease Control and Prevention. JAMA. 2020;323(13):1239. doi:10.1001/ jama.2020.2648

9. Giorgi Rossi P, Broccoli S, Angelini P. Angelini P and the Emilia-Romagna Covid19 working group. Case fatality rate in patients with COVID-19 infection and its relationship with length of follow up. J Clin Virol. 2020;128:104415. doi:10.1016/j.jcv.2020.104415

10. Baud D, Qi X, Nielsen-Saines K, Musso D, Pomar L, Favre G. Real estimates of mortality following COVID-19 infection. Lancet Infect Dis. 2020;S1473-3099(20)30195-X. doi:10.1016/S1473-3099(20)30195-X

11. Verity R, Okell LC, Dorigatti I, et al. Estimates of the severity of coronavirus disease 2019: a model-based analysis. Lancet Infect Dis. 2020:S1473-3099(20)30243-7. doi:10.1016/S1473-3099(20)30243-7

12. Hu Y, Sun J, Dai Z, et al. Prevalence and severity of coronavirus disease 2019 (COVID-19): A systematic review and meta-analysis (published online ahead of print, 2020 Apr 14). J Clin Virol. 2020;127:104371. doi:10.1016/j.jcv.2020.104371

13. Fu L, Wang B, Yuan T, et al. Clinical characteristics of coronavirus disease 2019 (COVID-19) in China: a systematic review and meta-analysis (published online ahead of print, 2020 Apr 10). J Infect. 2020;S0163-4453(20):30170-30175. doi:10.1016/j.jinf.2020.03.041

14. Riccardo F, Ajelli M, Andrianou XD, et al. Epidemiological characteristics of COVID-19 cases in Italy and estimates of the reproductive numbers one month into the epidemic. medRxiv. 2020. doi:10.1101/ 2020.04.08.20056861

15. Zhou F, Yu T, Du R, et al. Clinical course and risk factors for mortality of adult inpatients with COVID-19 in Wuhan, China: a retrospective cohort study. Lancet. 2020;395(10229):1054-1062. doi:10.1016/S0140-6736(20)30566-3

16. Wang K, Zhang Z, Yu M, Tao Y, Xie M. 15-day mortality and associated risk factors for hospitalized patients with COVID-19 in Wuhan, China: an ambispective observational cohort study. Intensive Care Med. 2020;1-3. doi:10.1007/s00134-020-06047-w

17. Wang L, He W, Yu X, et al. Coronavirus Disease 2019 in elderly patients: characteristics and prognostic factors based on 4-week follow-up. J Infect. 2020. doi:10.1016/j.jinf.2020.03.019

18. Richardson S, Hirsch JS, Narasimhan M, et al. Presenting characteristics, comorbidities, and outcomes among 5700 patients hospitalized with COVID-19 in the New York City Area. JAMA. 2020;323 (20):2052. doi:10.1001/jama.2020.6775
19. Grasselli G, Zangrillo A, Zanella A, et al. Baseline characteristics and outcomes of 1591 patients infected with SARS-CoV-2 admitted to ICUs of the Lombardy Region, Italy. JAMA. 2020;323(16):1574. doi:10.1001/jama.2020.5394

20. Charlson ME, Pompei P, Ales KL, MacKenzie CR. A new method of classifying prognostic comorbidity in longitudinal studies: development and validation. $J$ Chronic Dis. 1987;40(5):373-383. doi:10.1016/0021-9681(87)90171-8

21. Rajgor DD, Lee MH, Archuleta S, Bagdasarian N, Quek SC. The many estimates of the COVID-19 case fatality rate. Lancet Infect Dis. 2020; pii: S1473-3099(20)30244-9. doi:10.1016/S1473-3099(20)30244-9

22. Docherty AB, Harrison EM, Green CA, et al. Features of 20133 UK patients in hospital with covid-19 using the ISARIC WHO Clinical Characterisation Protocol: prospective observational cohort study. BMJ. 2020;369:m1985. doi:10.1136/bmj.m1985

23. Kim L, Garg S, O’Halloran A, et al. Risk Factors for Intensive Care Unit Admission and In-hospital Mortality among Hospitalized Adults Identified through the U.S. Coronavirus Disease 2019 (COVID-19)Associated Hospitalization Surveillance Network (COVID-NET) [published online ahead of print, 2020 Jul 16]. Clin Infect Dis. 2020:ciaa1012. doi:10.1093/cid/ciaa1012

24. Palaiodimos L, Kokkinidis DG, Li W, et al. Severe obesity, increasing age and male sex are independently associated with worse in-hospital outcomes, and higher in-hospital mortality, in a cohort of patients with COVID-19 in the Bronx, New York. Metabolism. 2020;108:154262. doi:10.1016/j.metabol.2020.154262

25 . Vincent JL, Taccone FS. Understanding pathways to death in patients with COVID-19. Lancet Respir Med. 2020;6:pii: S2213-2600(20) 30165-X. doi:10.1016/S2213-2600(20)30165-X

26. Johnson HC, Gossner CM, Colzani E, et al. Potential scenarios for the progression of a COVID-19 epidemic in the European Union and the European Economic Area, March 2020. Euro Surveill. 2020;25 (9):2000202. doi:10.2807/1560-7917.ES.2020.25.9.2000202

27. Odone A, Delmonte D, Scognamiglio T, Signorelli C. COVID-19 deaths in Lombardy, Italy: data in context. Lancet. 2020. doi:10.1016/ S2468-2667(20)30099-2

28. Presidenza del Consiglio dei Ministri. Dipartimento della Protezione Civile; 2020. Available from: https://github.com/pcm-dpc/COVID19/blob/master/schede-riepilogative/regioni/dpc-covid19-ita-schedaregioni-20200421.pdf.
Clinical Epidemiology

\section{Publish your work in this journal}

Clinical Epidemiology is an international, peer-reviewed, open access, online journal focusing on disease and drug epidemiology, identification of risk factors and screening procedures to develop optimal preventative initiatives and programs. Specific topics include: diagnosis, prognosis, treatment, screening, prevention, risk factor modification,

Submit your manuscript here: https://www.dovepress.com/clinical-epidemiology-journal systematic reviews, risk \& safety of medical interventions, epidemiology \& biostatistical methods, and evaluation of guidelines, translational medicine, health policies \& economic evaluations. The manuscript management system is completely online and includes a very quick and fair peer-review system, which is all easy to use. 